\title{
Mental health impacts among health workers during COVID-19 in a low resource setting: a cross-sectional survey from Nepal
}

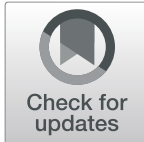

Pratik Khanal $^{1^{*}}$ (D, Navin Devkota ${ }^{2}$, Minakshi Dahal ${ }^{3}$, Kiran Paudel ${ }^{1}$ and Devavrat Joshi ${ }^{2}$

\begin{abstract}
Background: Health care workers exposed to COVID-19 might be at increased risk of developing mental health problems. The study aimed to identify factors associated with anxiety, depression and insomnia among health workers involved in COVID-19 response in Nepal.
\end{abstract}

Methods: This was a cross-sectional web-based survey conducted between April 26 and May 12, 2020. A total of 475 health workers participated in the study. Anxiety and depression were measured using a 14-item Hospital Anxiety and Depression Scale (HADS: 0-21) and insomnia was measured by using a 7-item Insomnia Severity Index (ISI: 0-28). Multivariable logistic regression analysis was done to determine the risk factors of mental health outcomes.

Results: Overall, $41.9 \%$ of health workers had symptoms of anxiety, 37.5\% had depression symptoms and 33.9\% had symptoms of insomnia. Stigma faced by health workers was significantly associated with higher odds of experiencing symptoms of anxiety (AOR: 2.47; 95\% Cl: 1.62-3.76), depression (AOR: 2.05; 95\% Cl: 1.34-3.11) and insomnia (AOR: 2.37; 95\% Cl: 1.46-3.84). History of medication for mental health problems was significantly associated with a higher likelihood of experiencing symptoms of anxiety (AOR: 3.40; 95\% Cl:1.31-8.81), depression (AOR: 3.83; 95\% Cl: 1.45-10.14) and insomnia (AOR: 3.82; 95\% Cl: 1.52-9.62) while inadequate precautionary measures in the workplace was significantly associated with higher odds of exhibiting symptoms of anxiety (AOR: 1.89; 95\% Cl: 1.12-3.19) and depression (AOR: 1.97; 95\% Cl: 1.16-3.37). Nurses (AOR: 2.33; 95\% Cl: 1.21-4.47) were significantly more likely to experience anxiety symptoms than other health workers.

Conclusion: The study findings revealed a considerate proportion of anxiety, depression and insomnia symptoms among health workers during the early phase of the pandemic in Nepal. Health workers facing stigma, those with history of medication for mental health problems, and those reporting inadequate precautionary measures in their workplace were more at risk of developing mental health outcomes. A focus on improving mental wellbeing of health workers should be immediately initiated with attention to reduction of stigma, ensuring an adequate support system such as personal protective equipments, and family support for those with history of mental health problems.

Keywords: Anxiety, COVID-19, Depression, Health workers, Insomnia, Mental health, Nepal

\footnotetext{
* Correspondence: pratikkhanal@iom.edu.np

${ }^{1}$ Institute of Medicine, Tribhuvan University, Kathmandu, Nepal

Full list of author information is available at the end of the article
} 


\section{Background}

The new coronavirus disease 2019 (COVID-19) is currently a threat to the global health in an unprecedented manner. Nepal, a South Asian country, is no exception and is affected by the outbreak with overwhelming effects on its economy and health system. The Government of Nepal initiated its response against COVID-19 immediately after its first reported case in the last week of January in a Nepalese traveller from China [1, 2]. As of June 29, 13,248 cases and 29 deaths had been reported in the country despite nationwide lockdown imposed from March 24, which continued for nearly 10 weeks [3].

The mental health impact of a disease outbreak is usually neglected during pandemic management although the consequences are costly [4]. Early evidence has shown that health workers directly involved in the diagnosis, treatment, and care of patients with COVID-19 are at risk of developing mental health symptoms [5-8]. Similar adverse psychological reactions were reported among health care workers in previous studies during the 2003 Severe Acute Respiratory Syndrome (SARS) outbreak $[9,10]$. The increasing number of confirmed cases and deaths, work burden, inadequate personal protective equipment (PPE), media coverage, lack of specific treatment, vulnerability to infection and having to stay in quarantine, as well as feelings of being inadequately supported in the workplace, can contribute to the mental burden of health workers [11].

Psychological wellbeing has an important impact on individuals' performance. The impact of COVID19 on mental health is well documented in various countries among different populations including health professionals [4]. However, evidence regarding the impact of the COVID-19 pandemic on health professionals is not available in Nepal. During the initial response to COVID-19, there were media reports regarding inadequate testing kits, and lack of PPEs $[12,13]$. At the work place, health workers require a support system to promote their mental wellbeing and their activity need to be continually monitored - this is crucial during health emergencies [14]. A timely assessment of mental health status and mental health needs of health workers during emergencies will help the management to respond and reduce psychological distress, and also align health workers to the patient needs. In this context, this study aimed to evaluate mental health outcomes among health care workers involved in the COVID19 response by quantifying the magnitude of symptoms of depression, anxiety and insomnia and by analysing potential risk factors associated with these symptoms.

\section{Methods}

\section{Study design and study participants}

A cross-sectional study was conducted via web online survey among health workers working in health facilities in Nepal. Data were collected from April 26 to May 122, 020. During the data collection period, Nepal experienced an increase in COVID-19 reported cases from 52 to 217. As of May 12, cases were reported from 19 out of 77 districts of Nepal.

Health professionals working in the management of COVID-19 response, in both public and private health facilities were recruited as study participants through online survey. A network of 25 hub hospitals are designated for COVID-19 management while other hospitals, primary health centres and health posts coordinate with these hub hospitals and run fever clinics for screening of COVID-19 cases. Health professionals included doctors, nurses, pharmacists, diagnostic personnel, paramedics and public health practitioners. A total of 501 responses were received out of which 26 were redundant and hence removed from the analysis. The final sample size of the study was 475 .

\section{Data collection methods}

The data collection involved two steps: i) identification of survey anchors for participant recruitment online, and ii) survey administration. In the first step, we identified social media platforms and health facility focal persons to recruit the participants followed by non-random sampling of participants interested to participate in the online survey. Online questionnaires on online Google forms were used to collect data from the participants. Study participants were encouraged to fill the online survey form in their leisure. To limit non-health worker's responses to the online survey, forms were only sent upon invitation to potential participants. The inclusion criteria were health workers aged 18 years and above and living in Nepal, and currently working in COVID-19 management. Participants were excluded if they were below 18 years of age, on leave or unable to participate due to physical or emotional distress.

\section{Study variables}

The dependent variables in the study included the status of anxiety, depression and insomnia. The independent variables included information about socio-demographic characteristics and work-related variables. The dependent variables and independent variables are presented in Table 1.

\section{Data collection measures}

Anxiety, depression and insomnia of the participants were assessed using the 14-item Hospital Anxiety and Depression Scale (HADS), and the 7-item Insomnia 
Table 1 Study variables

\begin{tabular}{|c|c|c|}
\hline S.N. & Variables & Categories of variables \\
\hline \multicolumn{3}{|c|}{ Dependent variables } \\
\hline 1 & Anxiety & Normal (0-7) and Anxiety (more than 7) based on Hospital Anxiety and Depression Scale \\
\hline 2 & Depression & Normal (0-7) and Depression (more than 7) based on Hospital Anxiety and Depression Scale \\
\hline 3 & Insomnia & $\begin{array}{l}\text { No clinically significant insomnia (0-7), Sub threshold insomnia (8-14), Moderate severity (15-21) and } \\
\text { Severe clinical insomnia ( } 22-28) \text { based on Insomnia Severity Index. For analysis purpose, a cut-off score } \\
\text { of } 10 \text { was taken. Absence (0-9) and Presence of insomnia ( } 10 \text { and above) }\end{array}$ \\
\hline \multicolumn{3}{|c|}{ Independent variables } \\
\hline \multicolumn{3}{|c|}{ Socio-demographic characteristics } \\
\hline 1 & Age & Up to 40 years, Above 40 years \\
\hline 2 & Gender & Male, Female \\
\hline 3 & Ethnicity & $\begin{array}{l}\text { Brahmin/Chhetri, Janajati, Madheshi and others. Adopted from Nepal's Health Management Information } \\
\text { System }\end{array}$ \\
\hline 4 & Educational qualification & Intermediate and below, Bachelor, Masters and above \\
\hline 5 & Profession & Doctors, Nurses, Others \\
\hline 6 & Marital status & Single, Ever married \\
\hline 7 & Type of family & Nuclear, Joint and Extended \\
\hline 8 & Living with child less than 15 years & Yes, No \\
\hline 9 & Living with elderly (above 60 years) & Yes, No \\
\hline 10 & $\begin{array}{l}\text { Having a family member with } \\
\text { chronic disease }\end{array}$ & Yes, No \\
\hline 11 & $\begin{array}{l}\text { History of medication for mental } \\
\text { health problem }\end{array}$ & Yes, No \\
\hline \multicolumn{3}{|c|}{ Work related variables } \\
\hline 1 & Work role & Frontline, second line \\
\hline 2 & Work experience & Up to 5 years, more than 5 years \\
\hline 3 & Type of health facility & Primary, secondary and tertiary \\
\hline 4 & $\begin{array}{l}\text { Precautionary measures in } \\
\text { workplace }\end{array}$ & Sufficient, insufficient \\
\hline 5 & $\begin{array}{l}\text { Aware of government incentive for } \\
\text { health workers }\end{array}$ & Yes, No \\
\hline 6 & Stigma faced due to COVID-19 & Yes, No, Do not want to answer \\
\hline 7 & Working in affected district & Yes, No (District having at least one confirmed case as affected district) \\
\hline 8 & Working overtime & Yes, No \\
\hline 9 & Change in regular job duty & Yes, No \\
\hline
\end{tabular}

Severity Index (ISI). Internal consistency of the tool was ascertained by calculating Cronbach's alpha, which was 0.81, 0.72 and 0.90 for anxiety, depression and insomnia respectively and considered sufficient $[15,16]$.

The HADS is a commonly used tool for measuring anxiety and depression in different settings in many countries including Nepal [17-22]. It has seven items each for measurement of anxiety and depression which are scored from 0 to 21 . The total scores of these tools were interpreted as normal (0-7), borderline abnormal (8-10) and abnormal (11-21). For analysis, score more than 7 was considered as the presence of anxiety and depression. Similarly, the score of ISI which records sleep outcome in the past 2 weeks was categorised as no clinically significant insomnia (0-7), subthreshold insomnia (8-14), moderate clinical insomnia (15-21) and severe clinical insomnia (22-28) as in studies done elsewhere $[8,23-26]$. For further analysis, a cut-off score of 10 was used to categorise the presence or absence of insomnia as suggested by Morin CM et al. [27].

\section{Data analysis}

Descriptive analysis was done by calculating frequency and percentages for categorical variables and mean and standard deviation for continuous variables. Chi-square test was used to determine the association between categorical independent variables and categorical dependent variables (Additional file 1). To determine 
potential factors associated with the outcome variable, multivariable logistic regression analysis was performed, adjusted odds ratio (AOR) and 95\% confidence interval (CI) were calculated. For adjusted regression analysis, those variables which were significant at a $10 \%$ significance level in bivariate analysis were included in the multivariable logistic regression analysis [28]. Similarly, the history of medication for a mental health problem was also fitted into the model regardless of the significance based on the prior knowledge [29]. The Variance Inflation Factor (VIF) was calculated before fitting into the model for each of the psychometric scales which showed no evidence of multicollinearity (less than 1.3).

In the multivariable logistic regression models, the effect of gender, ethnicity, profession, education, living with elderly, family member with chronic disease, precautionary measures in the workplace, faced stigma, worked overtime, awareness about government incentive and history of medication for mental health problem was adjusted to identify the factors associated with anxiety symptoms. Similarly for depression, the effect of age, ethnicity, profession, education, living with children, precautionary measures in the workplace, faced stigma, awareness about government incentive and history of medication for mental health problem was adjusted. Likewise for insomnia, the effect of age, ethnicity, profession, education, work experience, living in affected district, faced stigma, working overtime, awareness about government incentive and history of medication for mental health problem was adjusted.

\section{Ethics}

Ethical approval for the study was given by the Nepal Health Research Council (Reference number: 2192, 315/ 2020). Written digital consent was taken from study participants prior to completing the survey form. Participants gave their consent by ticking the designated box. Personal identifiers such as name were not collected during the study. The email address collected from the study participants was only used for quality control and not for analysis purposes.

\section{Results}

\section{Socio-demographic characteristic of study participants}

Of the study participants, $52.6 \%$ were female, $68.4 \%$ were in the age group of $20-29$ years and $65.9 \%$ belonged to the Brahmin/Chhetri ethnic group. The mean $( \pm \mathrm{SD})$ age of the participants was $28.20( \pm 5.80)$ years. More than two-thirds of health workers were either nurses (35.2\%) or doctors (33.9\%). The majority of the participants were single (62.9\%) and had a nuclear family structure (64.8\%). More than half of the participants $(54.5 \%)$ had a family member with a chronic disease condition, $25.1 \%$ were living with younger children and $34.3 \%$ had elderly people in the family. The percentage of health workers who had a history of medication for any kind of mental health conditions was $4.6 \%$ (Table 2).

\section{Work-related characteristics}

Regarding the type of health facility, 39\% worked in a central or provincial hospital, and $28.2 \%$ worked in a private hospital. Nearly half of the participants (45.3\%) mentioned working as frontline workers for COVID management while $70.7 \%$ had started their job within the last 5 years. The majority of the participants reported changes in their regular job duties $(70.3 \%)$ and insufficient precautionary measure in their workplace (78.9\%) during the outbreak. Around half of the participants (49.1\%) were working overtime. The proportion of health workers aware of government incentive scheme for health workers during COVID-19 was $56.8 \%$, of which $69.6 \%$ were dissatisfied with this scheme. More than half of the participants (53.7\%) faced stigma from the community members. Among those who faced stigma, they were stigmatised because of profession (49.8\%), accused of being a carrier of the disease (40.0\%), threatened $(5.9 \%)$ or asked to leave their rented place (4.3\%) (Table 3).

\section{Prevalence of anxiety, depression and insomnia}

More than one-third of the participants had some symptoms of anxiety (borderline: $23.6 \%$ and abnormal: $18.3 \%$ ). Similarly, $37.5 \%$ of the participants experienced symptoms of depression (borderline: $24 \%$ and abnormal: $13.5 \%)$. Likewise, symptoms of insomnia were prevalent in $33.9 \%$ of the participants (sub-threshold insomnia: 26.7\%, moderate insomnia: $5.7 \%$ and severe clinical insomnia: $1.5 \%)$. There was a significant difference in anxiety $(p<0.001)$ and depression $(p=0.001)$ across different types of profession. However, type of profession was not statistically significant with insomnia $(p=0.142)$. Nurses had a higher proportion of symptoms related to abnormal anxiety, abnormal depression and severe clinical insomnia than other professions (Table 4).

\section{Factors associated with anxiety, depression and insomnia among health workers}

Stigma experience among health workers was significantly associated with higher odds of experiencing symptoms of anxiety (AOR: 2.47; 95\% CI: 1.62-3.76), depression (AOR: 2.05; 95\% CI: 1.34-3.11) and insomnia (AOR: 2.37; 95\% CI: 1.46-3.84). History of medication for mental health problems was significantly associated with higher likelihood of experiencing symptoms of anxiety (AOR: 3.40; 95\% CI: 1.31-8.81), depression (AOR: 3.83; 95\% CI: 1.45-10.14) and insomnia (AOR: 3.82; 95\% CI: $1.52-9.62)$. Inadequate precautionary measures in the workplace was significantly associated with higher 
Table 2 Socio-demographic characteristics of study participants $(n=475)$

\begin{tabular}{|c|c|c|c|}
\hline Variables & Categories & Number & Percentage \\
\hline \multirow[t]{5}{*}{ Age (years) } & Mean $( \pm S D): 28.20( \pm 5.80)$ & & \\
\hline & $20-29$ & 325 & 68.4 \\
\hline & $30-39$ & 124 & 26.1 \\
\hline & $40-49$ & 19 & 4.0 \\
\hline & 50 and above & 7 & 1.5 \\
\hline \multirow[t]{2}{*}{ Sex } & Male & 225 & 47.4 \\
\hline & Female & 250 & 52.6 \\
\hline \multirow[t]{5}{*}{ Ethnicity } & Brahmin/Chhetri & 313 & 65.9 \\
\hline & Janjati & 110 & 23.2 \\
\hline & Madhesi & 29 & 6.1 \\
\hline & Dalit & 7 & 1.5 \\
\hline & Others & 16 & 3.4 \\
\hline \multirow[t]{4}{*}{ Education } & Technical school level & 8 & 1.7 \\
\hline & Intermediate & 86 & 18.1 \\
\hline & Bachelors & 277 & 58.3 \\
\hline & Masters and above & 104 & 21.9 \\
\hline \multirow[t]{6}{*}{ Position } & Nurse & 167 & 35.2 \\
\hline & Doctor & 161 & 33.9 \\
\hline & Paramedics & 81 & 17.1 \\
\hline & Laboratory staff & 19 & 4.0 \\
\hline & Pharmacist & 15 & 3.2 \\
\hline & Public health professional & 32 & 6.7 \\
\hline \multirow[t]{2}{*}{ Marital status } & Single & 299 & 62.9 \\
\hline & Ever married & 176 & 37.1 \\
\hline \multirow[t]{2}{*}{ Family type } & Nuclear & 308 & 64.8 \\
\hline & Joint & 167 & 35.2 \\
\hline \multirow[t]{2}{*}{ Living with children } & Yes & 119 & 25.1 \\
\hline & No & 356 & 74.9 \\
\hline \multirow[t]{2}{*}{ Living with older adults (> 60 years) } & Yes & 163 & 34.3 \\
\hline & No & 312 & 65.7 \\
\hline \multirow[t]{2}{*}{ Family member with a chronic medical condition } & Yes & 259 & 54.5 \\
\hline & No & 216 & 45.5 \\
\hline \multirow[t]{2}{*}{ History of medication for mental health } & Yes & 22 & 4.6 \\
\hline & No & 453 & 95.4 \\
\hline
\end{tabular}

odds of exhibiting symptoms of anxiety (AOR: 1.89; 95\% CI: 1.12-3.19) and depression (AOR: 1.97; 95\% CI: 1.163.37). As compared to Brahmin/Chhetri ethnic group, Janajati had significantly higher odds of having symptoms of anxiety (AOR $=2.34 ; 95 \% \mathrm{CI}: 1.44-3.81)$ and insomnia $(A O R=1.74 ; 95 \%$ CI: 1.04-2.91). Profession wise, nurses $(\mathrm{AOR}=2.33 ; 1.21-4.47$ ) had significantly higher odds of having anxiety symptoms than other health workers while doctors $(\mathrm{AOR}=0.57 ; 95 \% \mathrm{CI}$ : 0.33-0.99) had significantly lower odds of experiencing symptoms of depression than other health workers.
Younger health workers (AOR $=0.33$; 95\% CI: $0.12-$ 0.91 ) and those aware of the government incentive for health workers during COVID-19 (AOR $=0.51 ; 95 \% \mathrm{CI}$ : 0.34-0.78) were significantly less likely to exhibit symptoms of depression compared with older health workers and those not aware of such incentives. Regarding work experience, those who had less than 5 years' work experience $(\mathrm{AOR}=0.50 ; 95 \% \mathrm{CI}: 0.29-0.85)$ had lower odds of having symptoms of insomnia compared with those with experience of more than 5 years. Gender, education, living with elderly people, a family member 
Table 3 Work-related characteristics of the study participants $(n=475)$

\begin{tabular}{|c|c|c|c|}
\hline Variables & Category & Number & Percentage \\
\hline \multirow[t]{7}{*}{ Level of health institution } & Central hospital and province hospital & 185 & 39.0 \\
\hline & Private hospital & 134 & 28.2 \\
\hline & Health post & 45 & 9.5 \\
\hline & Community hospital & 27 & 5.7 \\
\hline & Primary hospital (under local government) & 20 & 4.2 \\
\hline & Primary Health centre & 19 & 4.0 \\
\hline & Managerial task of COVID19 & 45 & 9.5 \\
\hline \multirow[t]{2}{*}{ Type of health facility } & Primary & 84 & 17.7 \\
\hline & Secondary and tertiary & 391 & 82.3 \\
\hline \multirow[t]{2}{*}{ Work role } & Front line & 215 & 45.3 \\
\hline & Second line & 260 & 54.7 \\
\hline \multirow[t]{2}{*}{ Working experience (years) } & Up to 5 & 336 & 70.7 \\
\hline & $>5$ & 139 & 29.3 \\
\hline \multirow[t]{2}{*}{ Precautionary measures in the workplace } & Sufficient & 100 & 21.1 \\
\hline & Not sufficient & 375 & 78.9 \\
\hline \multirow[t]{3}{*}{ Experience of stigma due to occupation } & Yes & 255 & 53.7 \\
\hline & No & 199 & 41.9 \\
\hline & Don't want to answer & 21 & 4.4 \\
\hline \multirow[t]{4}{*}{ Type of major stigma experience $(n=255)$} & Stigmatised because of profession & 127 & 49.8 \\
\hline & Accused of being a carrier of disease & 102 & 40.0 \\
\hline & Threatened & 15 & 5.9 \\
\hline & Asked to leave rented place & 11 & 4.3 \\
\hline \multirow[t]{2}{*}{ Aware of government incentives for health workers } & Yes & 270 & 56.8 \\
\hline & No & 205 & 43.2 \\
\hline \multirow[t]{2}{*}{ Satisfied with government incentive $(n=270)$} & Yes & 82 & 30.4 \\
\hline & No & 188 & 69.6 \\
\hline \multirow[t]{2}{*}{ Change in regular job duties during covid19 } & Yes & 334 & 70.3 \\
\hline & No & 141 & 29.7 \\
\hline \multirow[t]{2}{*}{ Working overtime during COVID-19 } & Yes & 233 & 49.1 \\
\hline & No & 242 & 50.9 \\
\hline
\end{tabular}

Table 4 Prevalence of anxiety, depression and insomnia by study groups ( $n=475)$

\begin{tabular}{|c|c|c|c|c|c|c|}
\hline Mental health outcomes & Categories & Total N (\%) & Doctor $(n=161)$ & Nurse $(n=167)$ & $\begin{array}{l}\text { Other health workers } \\
(n=147)\end{array}$ & $P$-value * \\
\hline \multirow[t]{3}{*}{ Anxiety } & Normal & $276(58.1)$ & $106(65.4)$ & $73(43.7)$ & $97(66.4)$ & $<0.001$ \\
\hline & Borderline & $112(23.6)$ & $34(21.0)$ & $54(32.3)$ & $24(16.4)$ & \\
\hline & Abnormal & 87 (18.3) & $22(13.6)$ & $40(24.0)$ & $25(17.1)$ & \\
\hline \multirow[t]{3}{*}{ Depression } & Normal & $297(62.5)$ & $122(75.3)$ & $89(53.3)$ & $86(58.9)$ & 0.001 \\
\hline & Borderline & $114(24.0)$ & $27(16.7)$ & $46(27.5)$ & $41(28.1)$ & \\
\hline & Abnormal & $64(13.5)$ & $13(8.0)$ & $32(19.2)$ & $19(13.0)$ & \\
\hline \multirow[t]{4}{*}{ Insomnia } & No clinically significant & $314(66.1)$ & $115(71.0)$ & $98(58.7)$ & $101(69.2)$ & 0.142 \\
\hline & Sub threshold & $127(26.7)$ & $38(23.5)$ & $53(31.7)$ & $36(24.7)$ & \\
\hline & Moderate & $27(5.7)$ & $9(5.6)$ & $12(7.2)$ & $6(4.1)$ & \\
\hline & Severe & $7(1.5)$ & $0(0)$ & $4(2.4)$ & $3(2.1)$ & \\
\hline
\end{tabular}


with chronic disease, working overtime and awareness about government incentive was however not statistically significant with the presence of anxiety symptoms. Similarly, ethnicity, education and living with children were not statistically significant with the presence of depression symptoms. Likewise, age, profession, education, working in affected district, working overtime and awareness about government incentive was not statistically significant with the symptoms of insomnia (Tables 5, 6 and 7).

\section{Discussion}

This study examined the status of anxiety, depression and insomnia symptoms among health workers in Nepal during the early phase of the COVID19 pandemic. The prevalence of anxiety (41.9\%) and depression (37.5\%) symptoms among health workers in this study was higher than those found in a recent study conducted among the general population during COVID-19 pandemic in Nepal, which showed that $31 \%$ of respondents reported anxiety and 34\% of respondents reported depression [30]. This might be because health workers have a higher risk of acquiring COVID-19 infection in comparison to the general population, and also due to the stressful and demanding nature of the job. However, the prevalence of anxiety, depression and insomnia in this study was lower than that in health workers from China [5] where $44.6,50.4$ and $34.0 \%$ of health workers were reported to have anxiety, depression and insomnia respectively. China faced a major impact of COVID-19 and health facilities were overwhelmed with COVID-19 patients requiring hospitalisation and intensive care. The increased risk of infection and stressful environment might have contributed to higher mental health impacts among health workers in China than in Nepal $[5,8,31]$. Mental health outcomes among health workers affect their work performance and to address this, specialised mental health services are required $[8,32,33]$. The higher perceived risk and having to stay in quarantine during the epidemic might not just result in short term

Table 5 Factors associated with anxiety among health workers $(n=475)$

\begin{tabular}{|c|c|c|c|c|}
\hline Variables & Category & Anxiety N (\%) & Unadjusted OR $(95 \% \mathrm{Cl})$ & Adjusted OR (95\% Cl) \\
\hline \multirow[t]{2}{*}{ Gender } & Male & $76(38.2)$ & Ref & Ref \\
\hline & Female & $123(61.2)$ & $1.90(1.31-2.75)^{*}$ & $1.05(0.59-1.88)$ \\
\hline \multirow[t]{4}{*}{ Ethnicity } & Brahmin/Chhetri & 110 & Ref & Ref \\
\hline & Janajati & 69 & $2.71(1.75-4.20)^{*}$ & $2.34(1.44-3.81)^{*}$ \\
\hline & Madheshi & 10 & $0.97(0.44-2.16)$ & $1.11(0.47-2.59)$ \\
\hline & Others & 10 & $2.64(0.98-7.12)$ & $2.19(0.73-6.54)$ \\
\hline \multirow[t]{3}{*}{ Profession } & Doctor & 56 & $1.05(0.65-1.68)$ & $1.17(0.68-2.04)$ \\
\hline & Nurses & 94 & $2.55(1.61-4.04)^{*}$ & $2.33(1.21-4.47)^{*}$ \\
\hline & Others & 49 & Ref & Ref \\
\hline \multirow[t]{3}{*}{ Education } & Intermediate and below & 47 & Ref & Ref \\
\hline & Bachelor & 116 & $0.72(0.45-1.15)$ & $0.97(0.57-1.67)$ \\
\hline & Masters and above & 36 & $0.53(0.30-0.94)^{*}$ & $0.99(0.49-1.97)$ \\
\hline \multirow[t]{2}{*}{ Living with elderly } & Yes & 78 (39.2) & $1.45(0.99-2.12)$ & $1.43(0.92-2.22)$ \\
\hline & No & $121(60.1)$ & Ref & Ref \\
\hline \multirow[t]{2}{*}{ Family member with chronic disease } & Yes & $121(60.8)$ & $1.55(1.07-2.25)^{*}$ & $1.25(0.81-1.93)$ \\
\hline & No & $78(39.2)$ & Ref & Ref \\
\hline \multirow[t]{2}{*}{ Precautionary measures in the workplace } & Sufficient & $29(14.6)$ & Ref & Ref \\
\hline & Insufficient & $170(85.4)$ & $2.03(1.26-3.27)^{*}$ & $1.89(1.12-3.19)^{*}$ \\
\hline \multirow[t]{2}{*}{ Faced stigma } & Yes & $131(65.8)$ & $2.36(1.62-3.44)^{*}$ & $2.47(1.62-3.76)^{*}$ \\
\hline & No & $68(34.2)$ & Ref & Ref \\
\hline \multirow[t]{2}{*}{ Worked overtime } & Yes & $107(53.8)$ & $1.39(0.96-2.00)$ & $1.31(0.87-1.97)$ \\
\hline & No & $92(46.2)$ & Ref & Ref \\
\hline \multirow[t]{2}{*}{ Aware about government incentive } & Yes & $100(50.3)$ & $0.63(0.44-0.91)^{*}$ & $0.78(0.51-1.18)$ \\
\hline & No & $99(49.7)$ & Ref & Ref \\
\hline \multirow[t]{2}{*}{ History of medication } & Yes & $14(7.0)$ & $2.54(1.04-6.17)^{*}$ & $3.40(1.31-8.81)^{*}$ \\
\hline & No & $185(93.0)$ & Ref & Ref \\
\hline
\end{tabular}

*Significant at $p<0.05$ 
Table 6 Factors associated with depression among health workers $(n=475)$

\begin{tabular}{|c|c|c|c|c|}
\hline Variables & Category & Depression N (\%) & Unadjusted OR (95\% Cl) & Adjusted OR (95\% Cl) \\
\hline \multirow[t]{2}{*}{ Age (years) } & $20-40$ & $165(92.7)$ & $0.40(0.17-0.95)^{*}$ & $0.33(0.12-0.91)^{*}$ \\
\hline & $>40$ & $13(7.3)$ & Ref & Ref \\
\hline \multirow[t]{4}{*}{ Ethnicity } & Brahmin/Chhetri & $107(60.1)$ & Ref & Ref \\
\hline & Janajati & $51(28.7)$ & $1.51(0.98-2.33)$ & $1.19(0.74-1.93)$ \\
\hline & Madheshi & $9(5.1)$ & $0.87(0.38-1.97)$ & $1.03(0.43-2.49)$ \\
\hline & Others & $11(6.2)$ & $3.53(1.27-9.81)^{*}$ & $2.18(0.73-6.57)$ \\
\hline \multirow[t]{3}{*}{ Profession } & Doctor & $40(22.5)$ & $0.47(0.29-0.76)^{*}$ & $0.57(0.33-0.99)^{*}$ \\
\hline & Nurses & $78(43.8)$ & $1.26(0.80-1.97)$ & $1.25(0.76-2.06)$ \\
\hline & Others & $60(33.7)$ & Ref & Ref \\
\hline \multirow[t]{3}{*}{ Education } & Intermediate and below & $51(28.7)$ & Ref & Ref \\
\hline & Bachelor & $95(53.4)$ & $0.44(0.27-0.71)^{*}$ & $0.69(0.41-1.16)$ \\
\hline & Masters and above & $32(18.0)$ & $0.38(0.21-0.67)^{*}$ & $0.70(0.35-1.40)$ \\
\hline \multirow[t]{2}{*}{ Living with child } & Yes & $53(29.8)$ & $1.48(0.97-2.26)$ & $1.19(0.74-1.92)$ \\
\hline & No & $125(70.2)$ & Ref & Ref \\
\hline \multirow[t]{2}{*}{ Precautionary measures in the workplace } & Sufficient & $28(15.7)$ & 1 & Ref \\
\hline & Not sufficient & $150(84.3)$ & $1.71(1.06-2.78)^{*}$ & $1.97(1.16-3.37)^{*}$ \\
\hline \multirow[t]{2}{*}{ Faced stigma } & Yes & $116(65.2)$ & $2.13(1.45-3.12)^{*}$ & $2.05(1.34-3.11)^{*}$ \\
\hline & No & $57(34.8)$ & 1 & Ref \\
\hline \multirow[t]{2}{*}{ Aware about government incentive } & Yes & $82(46.1)$ & $0.50(0.34-0.72)^{*}$ & $0.51(0.34-0.78)^{*}$ \\
\hline & No & $96(53.9)$ & 1 & Ref \\
\hline \multirow[t]{2}{*}{ History of medication } & Yes & $14(7.9)$ & $3.08(1.27-7.51)^{*}$ & $3.83(1.45-10.14)^{*}$ \\
\hline & No & $164(92.1)$ & 1 & Ref \\
\hline
\end{tabular}

*Significant at $p<0.05$

impacts but also lead to long term mental health consequences among health workers [34-36]. There is thus a need to focus on mental wellbeing of health workers involved in the COVID-19 response.

Our findings unveiled that a considerable proportion of health workers in Nepal faced stigma related to COVID-19. Stigma significantly affected all the psychological outcomes among health workers. Stigma among health workers, who are already vulnerable to infection due to increased exposure, might affect their concentration on work. A similar finding was observed in Italy [37] where health workers facing stigma during COVID19 were found to have more burnout, fatigue and psychological distress. It is thus necessary to increase the morale of health workers who are stigmatised, in fear of getting infected or spreading infection to others. Importantly, the drivers and facilitators of stigma in health workers need to be understood for developing an effective response that might require extensive interventions $[38,39]$. Information directed at the public should thus integrate stigma reduction among health workers as an important strategy towards COVID-19 response.

In this study, inadequate precautionary measures were significantly associated with higher odds of anxiety and depression symptoms among health workers. Lack of precautionary measures including PPE can lead to compromised working conditions, a sense of insecurity and increased exposure to infections. As a large proportion of COVID-19 cases are asymptomatic [40], lack of a proper sense of protection among health workers might increase their psychological distress and affect their mental well-being. Three out of four health workers reporting inadequate precautionary measures in the workplace in this study reflects the vulnerability of health workers in Nepal to COVID-19 infections. Studies done globally [33, 41-43] have pointed out the need to equip health workers with PPE as well as provide psychological support to increase resilience to adverse mental health outcomes. This finding should persuade the government of the urgency of arranging adequate precautionary measures for reducing mental health burden among health workers in Nepal.

Our study findings showed that nurses had higher odds of exhibiting anxiety than other health professions. This might be attributed to the higher amount of time spent by them in patient care than other health workers. A study from China also showed that nurses, compared with other health professionals, experienced more 
Table 7 Factors associated with insomnia among health workers $(n=475)$

\begin{tabular}{|c|c|c|c|c|}
\hline Variables & Category & Insomnia N (\%) & Unadjusted OR $(95 \% \mathrm{Cl})$ & Adjusted OR $(95 \% \mathrm{Cl})$ \\
\hline \multirow[t]{2}{*}{ Age (years) } & $20-40$ & $108(92.3)$ & $0.45(0.19-1.08)$ & $0.45(0.16-1.29)$ \\
\hline & $>40$ & $9(7.7)$ & Ref & Ref \\
\hline \multirow[t]{3}{*}{ Ethnicity } & Brahmin/Chhetri & $70(59.8)$ & Ref & Ref \\
\hline & Janajati & $41(35.0)$ & $1.90(1.19-3.02)^{*}$ & $1.74(1.04-2.91)^{*}$ \\
\hline & Others & $6(5.1)$ & $0.52(0.21-1.28)$ & $0.40(0.15-1.06)$ \\
\hline \multirow[t]{3}{*}{ Profession } & Doctor & $31(26.5)$ & $0.72(0.42-1.25)$ & $1.24(0.65-2.35)$ \\
\hline & Nurses & $50(42.7)$ & $1.31(0.79-2.16)$ & $1.46(0.82-2.60)$ \\
\hline & Others & $36(30.8)$ & Ref & Ref \\
\hline \multirow[t]{3}{*}{ Education } & Intermediate and below & $32(27.4)$ & Ref & Ref \\
\hline & Bachelor & $65(55.6)$ & $0.59(0.36-0.99)^{*}$ & $0.69(0.39-1.24)$ \\
\hline & Masters and above & $20(17.1)$ & $0.46(0.24-0.88)^{*}$ & $0.53(0.24-1.18)$ \\
\hline \multirow[t]{2}{*}{ Work experience (year) } & Up to 5 & $71(60.7)$ & $0.54(0.35-0.84)^{*}$ & $0.50(0.29-0.85)^{*}$ \\
\hline & $>5$ & $46(39.3)$ & Ref & Ref \\
\hline \multirow[t]{2}{*}{ Affected district } & Yes & $94(80.3)$ & $1.63(0.98-2.71)$ & $1.55(0.89-2.68)$ \\
\hline & No & $23(19.7)$ & Ref & Ref \\
\hline \multirow[t]{2}{*}{ Faced stigma } & Yes & $80(68.4)$ & $2.26(1.45-3.52)^{*}$ & $2.37(1.46-3.84)^{*}$ \\
\hline & No & 37 (31.6) & Ref & Ref \\
\hline \multirow[t]{2}{*}{ Aware about government incentive } & Yes & $58(49.6)$ & $0.68(0.45-1.03)$ & $0.66(0.41-1.05)$ \\
\hline & No & $59(50.4)$ & 1 & Ref \\
\hline \multirow[t]{2}{*}{ Working overtime } & Yes & $69(59.0)$ & $1.70(1.11-2.60)^{*}$ & $1.53(0.96-2.42)$ \\
\hline & No & $48(41.0)$ & 1 & Ref \\
\hline \multirow[t]{2}{*}{ History of medication } & Yes & $12(10.3)$ & $3.98(1.67-9.47)^{*}$ & $3.82(1.52-9.62)^{*}$ \\
\hline & No & 105 (89.7) & 1 & Ref \\
\hline
\end{tabular}

*Significant at $p<0.05$

unfavourable mental health outcomes [5]. Similar findings were found during the SARS epidemic in Canada [44] where nurses experienced more psychological distress due to fear, social isolation and work stress. The mental health status of health professionals should thus be closely monitored by the employing health institutions including managing their workload, providing emotional support and responding to their personal needs.

In our study, health workers who had a history of medication for mental health problems had higher odds of exhibiting anxiety, depression and insomnia symptoms compared with those without such history. A similar finding was observed in a study conducted in China where health workers with a history of mental health problems were more likely to have anxiety, depression and stress [29]. Family and organisational support will be required for those health workers as the current pandemic might make them more vulnerable to a deterioration in their mental health conditions [45, 46].

In this study, gender, work role, marital status, and type of family, living with children, living with elderly people, having a family member with chronic disease, type of health facility, change in duties and working overtime had no significant effect on any mental health outcomes. As our study was conducted in the early phase of the pandemic when no mortality was documented and most of the cases had mild symptoms, working role might not have contributed to a significant difference in mental health outcomes. The other reason could be that health workers working in both frontline and second line might feel equally vulnerable to COVID-19 associated mental health outcomes during the early phase of pandemic. Further studies might be required to confirm these findings as the association might vary over the course of the epidemic in the country.

\section{Recommendations}

The unprecedented challenge brought by COVID-19 pandemic is unique in Nepal and a major pressure to its health system after the 2015 Gorkha Earthquake. Health workers in Nepal are currently working under extreme pressure amidst limited health resources such as inadequate staffing, just over 3000 isolation beds and 840 ventilators (increased from 300 ventilators at the beginning of the epidemic) for the population of 29 million [3, 47, 48]. 
It is noteworthy that mental health has not received adequate attention from the government despite its high burden [49]. Based on the study findings, we put forward the following recommendations for improving the mental well-being of health workers in Nepal. Firstly, the reduction of stigma among health workers working in COVID19 response should be prioritised through the mobilization of mass media and community engagement strategy. Provision should be made for living arrangements in the vicinity of health facilities if possible, which may help reduce the stigma faced by the health workers at their residence and neighborhood. This may also reduce the guilt and stress of being a potential carrier and exposing the family members to infection among health workers.. In conditions, where this is not possible,, strict measures against stigmatisation and activities such as forcing health workers to leave their rented home should be taken .. Secondly, there should be an enabling work environment with a good support system, adequate availability of PPE, proper training of health workers on management of COVID-19 and focus on incentives which boost their work morale. It is necessary to provide educational interventions for clearing of doubts of healthcare workers about COVID-19 and provide adequate logistical support to increase protection. Thirdly, personal and family support might be required especially in those who have a history of medication for mental health problems. Finally, psychological intervention with a focus on health workers should be a part of preparedness to reduce its impact not only on their well-being but also on the health system at large.

\section{Study limitations}

The study has some limitations which need to be acknowledged. Firstly, the study was conducted during the early phase of pandemic and thus the mental health outcomes might still reflect conditions existing before the pandemic. The relative contribution of the pandemic to the increase in mental health disorders needs to be evaluated using a longitudinal study design. Secondly, there might have been the introduction of selection bias as those health workers without internet access, older health workers, and those who might have been busy in their work duties might not have participated in the study. Thirdly, there might be respondent bias as the findings were self-reported by health workers and based on a subjective scale. Importantly, the tool used in the study should be taken into consideration while reporting mental health outcomes. Although the history of mental illness and medications taken for any kind of mental illness was included in the questionnaire, specific type of mental illness was not identified, which may or may not have affected the current symptoms of anxiety, depression and insomnia. Despite limitations, this study provides early evidence on the mental health status among health workers during the COVID-19 pandemic in Nepal, which should be of interest to policymakers, health facility managers and those involved in the response to COVID-19 or anyfuture epidemic.

\section{Conclusions}

This study reported a high prevalence of symptoms of anxiety, depression and insomnia among health workers in Nepal during the initial phase of the pandemic. More than half of the health workers faced stigma and only one out of five health workers reported precautionary measures in their workplace as sufficient. Stigma and history of medication for mental health problems was significantly associated with all the mental health outcomes while inadequate precautionary measures was associated with higher odds of having anxiety and depression symptoms. Nurses had higher odds of developing anxiety than other health workers. Improving mental wellbeing of health workers is recommended by focusing on stigma reduction, equipping health workers with protective measures, as well as ensuring personal and family support for those with a history of mental health issues.

\section{Supplementary information}

Supplementary information accompanies this paper at https://doi.org/10. 1186/s12992-020-00621-z.

Additional file 1: Additional Table 1. Anxiety and its associated factors. Additional Table 2. Depression and its associated factors. Additional Table 3. Insomnia and its associated factors

\section{Abbreviations}

AOR: Adjusted Odds Ratio; Cl: Confidence interval; COVID-19: Corona virus disease 2019; HADS: Hospital Anxiety Depression Scale; ISI: Insomnia Severity Index; MERS: Middle East Respiratory Syndrome; PPE: Personal protective equipment; SARS: Severe Acute Respiratory Syndrome; SD: Standard deviation; VIF: Variance Inflation Factor

\section{Acknowledgements}

The authors would like to acknowledge all the health workers involved in the study and the Policy, Planning and Monitoring Division of Ministry of Health and Population for providing us a letter of support for the study. We are also grateful to Shiva Raj Mishra and Ms. Anna Durrance-Bagale for reviewing the manuscript.

\section{Authors' contributions}

PK, ND and KP conceived the concept and design of the study. ND and KP conducted the survey while PK and MD conducted data analysis. PK wrote the first draft, which underwent substantial revision based on the inputs from all other authors. DJ supervised the whole study process. All the authors have read, reviewed and endorsed the final version of the manuscript.

\section{Funding}

None.

\section{Availability of data and materials}

All data generated during this study are included in the manuscript and the supplementary file. 


\section{Ethics approval and consent to participate}

Ethical approval for this study was provided by the Nepal Health Research Council, Kathmandu, Nepal (Registration number: 2192; 315/2020) while a letter of support was obtained from Ministry of Health and Population. An informed e-consent was obtained from individual participants. Study participants were informed clearly about their freedom to opt out of the study at any point of time without providing justification for doing so.

\section{Consent for publication}

Not applicable.

\section{Competing interests}

Authors have no competing interest associated with this paper. The author's affiliation does not necessarily reflect the view of their employing organisations. The authors prepared a policy brief of 2 pages based on preliminary findings and have shared it with the Ministry of Health and Population.

\section{Author details}

${ }^{1}$ Institute of Medicine, Tribhuvan University, Kathmandu, Nepal. ${ }^{2}$ National Academy for Medical Sciences, Kathmandu, Nepal. ${ }^{3}$ Center for Research on Environment, Health and Population Activities (CREHPA), Kathmandu, Nepal.

Received: 30 June 2020 Accepted: 17 September 2020

\section{Published online: 25 September 2020}

\section{References}

1. Bastola A, Sah R, Rodriguez-Morales AJ, Lal BK, Jha R, Ojha HC, Shrestha B, Chu DKW, Poon LLM, Costello A, et al. The first 2019 novel coronavirus case in Nepal. Lancet Infect Dis. 2020;20(3):279-80. https://doi.org/10.1016/S14733099(20)30067-0

2. Shrestha R, Shrestha S, Khanal P, Bhuvan KC. Nepal's first case of COVID-19 and public health response. J Travel Med. 2020. https://doi.org/10.1093/jtm/ taaa024.

3. Health Emergency Operation Center. Health sector response to COVID-19. 2020. https://heoc.mohp.gov.np/update-on-novel-corona-virus-covid-19/ (accessed 6/29/2020).

4. Naser AY, Dahmash EZ, Al-Rousan R, Alwafi H, Alrawashdeh HM, Ghoul I, Abidine A, Bokhary MA, HT AL-H, Ali D. Mental health status of the general population, healthcare professionals, and university students during 2019 coronavirus disease outbreak in Jordan: a cross-sectional study. medRxiv. 2020;10(8):e01730.

5. Lai J, Ma S, Wang Y, Cai Z, Hu J, Wei N, Wu J, Du H, Chen T, Li R. Factors associated with mental health outcomes among health care workers exposed to coronavirus disease 2019. JAMA Netw Open. 2020;3(3):e203976.

6. Rajkumar RP. COVID-19 and mental health: a review of the existing literature. Asian J Psychiatr. 2020;52(20):102066..

7. Spoorthy MS. Mental health problems faced by healthcare workers due to the COVID-19 pandemic-a review. Asian J Psychiatr. 2020;51:102119.

8. Kang L, Ma S, Chen M, Yang J, Wang Y, Li R, Yao L, Bai H, Cai Z, Yang BX. Impact on mental health and perceptions of psychological care among medical and nursing staff in Wuhan during the 2019 novel coronavirus disease outbreak: A cross-sectional study. Brain Behav Immun. 2020;87:11-7.

9. Bai $Y$, Lin C-C, Lin C-Y, Chen J-Y, Chue C-M, Chou P. Survey of stress reactions among health care workers involved with the SARS outbreak. Psychiatr Serv. 2004;55(9):1055-7.

10. Nickell LA, Crighton EJ, Tracy CS, Al-Enazy H, Bolaji Y, Hanjrah S, Hussain A Makhlouf S, Upshur RE. Psychosocial effects of SARS on hospital staff: survey of a large tertiary care institution. Cmaj. 2004;170(5):793-8.

11. Neto MLR, Almeida HG, JDa E, Nobre CB, Pinheiro WR, de Oliveira CRT, da Costa Sousa I, OMML L, NNR L, Moreira MM. When health professionals look death in the eye: the mental health of professionals who deal daily with the 2019 coronavirus outbreak. Psychiatry Res. 2020;288:112972.

12. Ramu Sapkota. Hospital staff in Nepal at the frontlines of the battle against COVID-19 lack protective gear. 2020. https://www.nepalitimes.com/herenow/protecting-those-who-protect-us-from-the-epidemic/.

13. Deo Narayan Shah. Health workers in Province 1 demand facilities at hospitals to treat Covid-19 patients. 2020. https://tkpo.st/2UiyJft.

14. Greenberg N, Docherty M, Gnanapragasam S, Wessely S. Managing mental health challenges faced by healthcare workers during covid-19 pandemic BMJ. 2020;368:m1211.
15. Tavakol M, Dennick R. Making sense of Cronbach's alpha. Int J Med Educ. 2011:2:53.

16. Santos JRA. Cronbach's alpha: a tool for assessing the reliability of scales. $J$ Ext. 1999:37(2):1-5

17. Höglund P, Hakelind C, Nordin S. Severity and prevalence of various types of mental ill-health in a general adult population: age and sex differences. BMC Psychiatry. 2020;20(1):1-11.

18. Zigmond AS, Snaith RP. The hospital anxiety and depression scale. Acta Psychiatr Scand. 1983;67(6):361-70.

19. Værøy H. Depression, anxiety, and history of substance abuse among Norwegian inmates in preventive detention: reasons to worry? BMC Psychiatry. 2011;11(1):40.

20. Duko B, Gebeyehu A, Ayano G. Prevalence and correlates of depression and anxiety among patients with tuberculosis at WolaitaSodo University hospital and Sodo health Center, WolaitaSodo, South Ethiopia, cross sectional study. BMC Psychiatry. 2015;15(1):214

21. Sharma A, Zhang J. Depression and its predictors among breast cancer patients in Nepal. J Psychiatry. 2015;16:1.

22. Manandhar K, Risal A, Steiner TJ, Holen A, Koju R, Linde M. Estimating the prevalence and burden of major disorders of the brain in Nepal: methodology of a nationwide population-based study. J Head Pain. 2014; 15(1):52.

23. Mohammadi $H$, Naghdi $H$, Yazdani N, Zakiei A, Najafi F, Khazaie H. Prediction of sleep quality and insomnia severity by psychological disorders and acute stress among earthquake survivors in Sarpol-e Zahab, Iran, 2017. Arch Trauma Res. 2019:8(2):93.

24. Bastien $\mathrm{CH}$, Vallières $\mathrm{A}$, Morin CM. Validation of the insomnia severity index as an outcome measure for insomnia research. Sleep Med. 2001;2(4):297-307.

25. Bluestein D, Rutledge CM, Healey AC. Psychosocial correlates of insomnia severity in primary care. J Am Board Fam Med. 2010;23(2):204-11.

26. Veqar Z, Hussain ME. Validity and reliability of insomnia severity index and its correlation with Pittsburgh sleep quality index in poor sleepers among Indian university students. Int J Adolesc Med Health. 2017;32(1)

27. Morin $\mathrm{CM}$, Belleville $\mathrm{G}$, Bélanger $\mathrm{L}$, Ivers $\mathrm{H}$. The insomnia severity index: psychometric indicators to detect insomnia cases and evaluate treatment response. Sleep. 2011:34(5):601-8.

28. Bursac Z, Gauss CH, Williams DK, Hosmer DW. Purposeful selection of variables in logistic regression. Source Code Biol Med. 2008:3:17.

29. Zhu Z, Xu S, Wang H, Liu Z, Wu J, Li G, Miao J, Zhang C, Yang Y, Sun W. Zhu S. COVID-19 in Wuhan: Sociodemographic characteristics and hospital support measures associated with the immediate psychological impact on healthcare workers. E Clin Med. 2020;24:100443.

30. Sigdel A, Bista A, Bhattarai N, Poon BC, Giri G, Marqusee H. Depression, Anxiety and Depression-anxiety comorbidity amid COVID19 Pandemic: An online survey conducted during lockdown in Nepal. medRxiv. 2020;1-27. https://www.medrxiv.org/content/10.1101/2020. 04.30.20086926v1.full.pdf.

31. Liu Q, Luo D, Haase JE, Guo Q, Wang XQ, Liu S, Xia L, Liu Z, Yang J, Yang BX. The experiences of health-care providers during the COVID-19 crisis in China: a qualitative study. Lancet Glob Health. 2020;8(6):e790-e798.

32. Weaver MD, Vetter C, Rajaratnam SM, O'Brien CS, Qadri S, Benca RM, Rogers $A E$, Leary EB, Walsh JK, Czeisler CA. Sleep disorders, depression and anxiety are associated with adverse safety outcomes in healthcare workers: a prospective cohort study. J Sleep Res. 2018;27(6):e12722.

33. Du J, Dong L, Wang T, Yuan C, Fu R, Zhang L, Liu B, Zhang M, Yin Y, Qin J. Psychological symptoms among frontline healthcare workers during COVID19 outbreak in Wuhan. Gen Hosp Psychiatry. 2020. https://www.ncbi.nlm. nih.gov/pmc/articles/PMC7194721/pdf/main.pdf.

34. Liu X, Kakade M, Fuller CJ, Fan B, Fang Y, Kong J, Guan Z, Wu P. Depression after exposure to stressful events: lessons learned from the severe acute respiratory syndrome epidemic. Compr Psychiatry. 2012;53(1):15-23. https:// doi.org/10.1016/j.comppsych.2011.02.003.

35. Wu P, Fang Y, Guan Z, Fan B, Kong J, Yao Z, Liu X, Fuller CJ, Susser E, Lu J. The psychological impact of the SARS epidemic on hospital employees in China: exposure, risk perception, and altruistic acceptance of risk. Can J Psychiatr. 2009;54(5):302-11.

36. Lee SM, Kang WS, Cho A-R, Kim T, Park JK. Psychological impact of the 2015 MERS outbreak on hospital workers and quarantined hemodialysis patients. Compr Psychiatry. 2018;87:123-7.

37. Ramaci T, Barattucci M, Ledda C, Rapisarda V. Social stigma during COVID-19 and its impact on HCWs outcomes. Sustainability. 2020;12(9):3834. 
38. Logie $\mathrm{CH}$, Turan JM. How do we balance tensions between COVID-19 public health responses and stigma mitigation? Learning from HIV research. AIDS Behav. 2020;24(7):2003-2006.

39. Stangl AL, Earnshaw VA, Logie CH, van Brakel W, Simbayi LC, Barré Dovidio JF. The health stigma and discrimination framework: a global, crosscutting framework to inform research, intervention development, and policy on health-related stigmas. BMC Med. 2019;17(1):31.

40. Day M. Covid-19: four fifths of cases are asymptomatic, China figures indicate. United Kingdom: British Medical Journal Publishing Group; 2020.

41. Chen Q, Liang M, Li Y, Guo J, Fei D, Wang L, He L, Sheng C, Cai Y, Li X. Mental health care for medical staff in China during the COVID-19 outbreak. Lancet Psychiatry. 2020;7(4):e15-6.

42. Liu C-Y, Yang Y-Z, Zhang X-M, Xu X, Dou Q-L, Zhang W-W, Cheng AS. The prevalence and influencing factors in anxiety in medical workers fighting COVID-19 in China: a cross-sectional survey. Epidemiol Infect. 2020:1-17.

43. Park S-C, Park YC. Mental health care measures in response to the 2019 novel coronavirus outbreak in Korea. Psychiatry Investig. 2020;17(2):85.

44. Maunder RG, Lancee WJ, Rourke S, Hunter JJ, Goldbloom D, Balderson K, Petryshen P, Steinberg R, Wasylenki D, Koh D, et al. Factors associated with the psychological impact of severe acute respiratory syndrome on nurses and other hospital workers in Toronto. Psychosom Med. 2004;66(6):938-42. https://doi.org/10.1097/01.psy.0000145673.84698.18.

45. Francis JL, Moitra E, Dyck I, Keller MB. The impact of stressful life events on relapse of generalized anxiety disorder. Depress Anxiety. 2012;29(5):386-91. https://doi.org/10.1002/da.20919.

46. Yang L, Zhao Y, Wang Y, Liu L, Zhang X, Li B, Cui R. The effects of psychological stress on depression. Curr Neuropharmacol. 2015;13(4):494504. https://doi.org/10.2174/1570159×1304150831150507.

47. Paneru HR. Intensive care units in the context of COVID-19 in Nepal: current status and need of the hour. J Soc Anesthesiol Nepal. 2020;7(1):e291.

48. IANS. Nepal faces shortage of vital medical supplies. 2020. https://www. outlookindia.com/newsscroll/nepal-faces-shortage-of-vital-medicalsupplies/1853189 (accessed 6/10/2020).

49. Mishra SR, Khanal P, Khanal V. Sustained neglect in mental health during Nepal's crises. Health Prospect. 2018;17(1):4-7.

\section{Publisher's Note}

Springer Nature remains neutral with regard to jurisdictional claims in published maps and institutional affiliations.

Ready to submit your research? Choose BMC and benefit from:

- fast, convenient online submission

- thorough peer review by experienced researchers in your field

- rapid publication on acceptance

- support for research data, including large and complex data types

- gold Open Access which fosters wider collaboration and increased citations

- maximum visibility for your research: over $100 \mathrm{M}$ website views per year

At BMC, research is always in progress.

Learn more biomedcentral.com/submissions 